\title{
Article
}

\section{Testing of Multistep Soil Washing for Radiocesium-Contaminated Soil Containing Plant Matter}

\author{
Masafumi FUNAKAWA ${ }^{1, *}$, Akihiro TAGAWA ${ }^{2}$ and Nobuyasu OKUDA ${ }^{3}$ \\ ${ }^{1}$ Environmental Engineering Department, Takenaka Corporation, 1-1-1 Shinsuna, Koto-ku, Tokyo 136-0075, Japan \\ ${ }^{2}$ Headquarters of Fukushima Partnership Operations, Japan Atomic Energy Agency, 2-2-2 Uchisaiwai-cho, Chiyoda-ku, Tokyo \\ 100-0011, Japan \\ ${ }^{3}$ Takenaka Research and Development Institute, Takenaka Corporation, 1-5-1 Otsuka, Inzai-shi, Chiba 270-1395, Japan
}

\begin{abstract}
Decontamination work following radiocesium exposure requires a vast reduction in the amount of contaminated soil generated. The current study subjected 4 types of contaminated soil with different properties to multistep soil washing under the same conditions. This study also determined the effectiveness of radiocesium decontamination and the extent to which the amount of contaminated soil was reduced. In addition, the effectiveness of plant matter separation, adsorbent addition, and grinding as part of multistep soil washing was determined using the same contaminated soil. Results of testing indicated that the rate of radiocesium decontamination ranged from 73.6 to $89.2 \%$ and the recovery rate ranged from 51.5 to $84.2 \%$ for twice-treated soil, regardless of the soil properties or cesium level. Plant matter in soil had a high radiocesium level. However, there was little plant matter in our soil sample. Therefore, plant matter separation had little effect on the improvement in the percentage of radiocesium decontamination of twice-treated soil. Soil surface grinding improved the radiocesium decontamination of twice-treated soil. However, radiocesium in soil tightly bound with minerals in the soil; thus, the addition of an adsorbent also failed to improve radiocesium decontamination.
\end{abstract}

KEYWORDS: decontamination, radiocesium-contaminated soil, multistep soil washing, plant matter, adsorbent, grinding

\section{Introduction}

The accident at the Tokyo Electric Power Company's Fukushima Daiichi Nuclear Power Plant, caused by the Great East Japan Earthquake on March 11th, 2011, released radioactive materials (mainly ${ }^{134} \mathrm{Cs}$, ${ }^{137} \mathrm{Cs}$ and ${ }^{131} \mathrm{I}$ ) over a wide area, making the reduction of the influence of environmental pollution on human health and the environment a challenging task. Investigation of the contamination and studies of decontamination technology were conducted for more than a year after the accident, and the removal of contamination by ${ }^{134} \mathrm{Cs}$ and ${ }^{137} \mathrm{Cs}$ (hereinafter referred to as "radioactive Cs") is now due to begin in earnest. According

\footnotetext{
* Corresponding author, E-mail: funakawa.masafumi@takenaka.co.jp

DOI : 10.15669/fukushimainsights.Vol.4.125

(C) 2021 Atomic Energy Society of Japan. All rights reserved.

Originally published in Transactions of the Atomic Energy Society of Japan (ISSN 1347-2879), Vol. 11, No. 4, p.272-280

(2012) in Japanese. (Japanese version accepted: August 22, 2012)
} 
to the decontamination-related guidelines ${ }^{1)}$, surface soil removal is the main recommended soil decontamination method. Plowing and removing the surface soil enables the soil to be decontaminated elsewhere. However, all of the decontaminated topsoil needs to be placed in interim storage facilities and, therefore, there is a possibility that the amount of radioactive Cs-contaminated soil will need to be reduced before this stage.

Soil washing can potentially reduce the amount of radioactive Cs-contaminated soil. Soil washing is a technology that has been applied in many cases to soils contaminated by heavy metals such as lead and arsenic, as well as oil ${ }^{2}$. In general, contaminants are present on the surface of soil particles, and the concentration of contaminants tends to be higher in clay and silt, which have large surface-to-weight and surface-to-volume ratios due to their small particle size, than in sand and gravel fractions, which have a larger particle size ${ }^{2)}$. The soil washing treatment recovers the sand with a larger particle size and gravel fractions as purified soil, and recovers the clay and silt fractions with a smaller particle size as a dehydrated cake which concentrates the contaminants. This is done by cleaning the contaminated soil mechanically with a wash solution, such as water. This is done by cleaning the contaminated soil mechanically with a wash solution, such as water. Since radioactive Cs tends to be adsorbed by the fine-particle fractions in the soil ${ }^{3}$, soil washing is expected to decontaminate radioactive Cs-contaminated soil.

The multistep soil washing described in this paper is a method to separate radioactive Cs-contaminated soil, containing plant matter, into processed twice-treated soil, a dehydrated cake in which the radioactive $\mathrm{Cs}$ is concentrated, and drainage water, by washing the contaminated soil according to the following process: (1) "Initial washing process" to slurry the contaminated soil, (2) "Plant matter separation process" to separate plant matter from the slurry and collect the once-treated soil, and (3) "Second washing process" to add water and an adsorbent into the once-treated soil and grind it. In particular, the plant matter separation process and the second washing process are expected to produce the following effects:

In the plant matter separation process, organic matter to which radioactive $\mathrm{Cs}$ is adsorbed is selectively separated and eliminated securely (with a high degree of accuracy) to improve decontamination and reduce the amount of soil to be processed.

In the second washing process, the surface of soil particles is ground to exfoliate the adsorbed radioactive $\mathrm{Cs}$ in order to enhance the decontamination effect. In addition, an adsorbent, the particle size of which is controlled, is added so that the radioactive Cs is adsorbed to the adsorbent rather than the soil particles. This allows the radioactive Cs to be collected as a dehydrated cake, even if water-soluble radioactive Cs is present in the soil.

As a result of dividing the soil washing treatment into three processes, the removal of radioactive Cs is improved and only the separated plant matter and the dehydrated cake need to be placed in interim storage facilities after soil washing. Therefore, the amount of radioactive Cs-contaminated soil is expected to be reduced.

In this paper, the multistep soil washing experimental results are reported. These experiments were conducted using four types of radioactive Cs-contaminated soil (hereinafter referred to as "contaminated soil"), to clarify the effectiveness of radioactive Cs removal, and the effect of the separation of fine-particle fractions through the separation of plant matter and physical grinding on the removal of radioactive $\mathrm{Cs}$, as well as to quantify the reduction of contaminated soil by the multistep soil washing process. 


\section{Experimental Methods}

\section{Radioactive Cs-contaminated Soils}

The contaminated soils used for the soil washing tests were collected from two locations: three samples from Fukushima Prefecture (Date, Fukushima and Minamisoma Cities) and one from Inzai City, Chiba Prefecture on December 14th-16th and 19th, 2012. At each sampling location, the contaminated soils were sampled by screening the soil using a stainless steel testing screen with a $9.5 \mathrm{~mm}$ mesh after removing the top $1.0-1.5 \mathrm{~cm}$ of soil using a long-shank sickle to eliminate pebbles (diameter $>9.5 \mathrm{~mm}$ ) and plant matter. The soils collected in Date and Fukushima cities are classified as lowland soils, and the ones collected in Minamisoma and Inzai cities are classified as andosols ${ }^{4)}$.

In this paper, the contaminated soils collected from the cities of Date, Fukushima, Minamisoma and Inzai are referred to as Soils A-D, respectively.

\section{Soil Washing Test}

Seven soil washing tests were conducted. Table 1 contains the test parameters. In Cases 1-4, the soil washing test was conducted on the four contaminated soils from A to D with different radioactive Cs concentrations, soil properties, and plant matter mixing conditions, using the same washing process (Protocol 1) to compare the decontamination effects achieved by washing soils with different properties. In addition, in Case 1 and Cases 5-7, the soil washing test was conducted on four samples of contaminated soil A, using different plant matter separation and second washing process conditions (Protocols 1-4) to compare the decontamination effects achieved by the plant matter separation and the second washing process. The conditions changed were: (1) Application of the plant matter separation process, (2) addition of an adsorbent, and (3) use of the grinding process. In this paper, the soil washing procedure in which plant matter separation, adsorbent addition, and grinding were all implemented is referred to as "Protocol 1"; "Protocol 2" is identical to Protocol 1 except for the omission of the plant matter separation process. In "Protocol 3", an adsorbent was not added during the test.

\section{Soil Washing Treatment Test Method}

For the initial washing, $10 \mathrm{~kg}$ of contaminated soil and $10 \mathrm{~kg}$ of water were placed in a drum washer (Kikosha Co., Ltd., KDW0602), and the washing process was conducted for one minute at $40 \mathrm{rpm}$. After the initial washing, the slurry was moved to a $20 \mathrm{~L}$ plastic bucket and agitated to separate the plant matter using a stainless steel testing screen with a $9.5 \mathrm{~mm}$ mesh. The remaining slurry was gravity-separated, at the classification point of $75 \mu \mathrm{m}$, to separate

Table 1 Test cases

\begin{tabular}{|c|c|c|c|c|c|c|c|c|}
\hline \multicolumn{2}{|c|}{ Case number } & Case 1 & Case 2 & Case 3 & Case 4 & Case 5 & Case 6 & Case 7 \\
\hline \multicolumn{2}{|c|}{ Soil } & Soil A & Soil B & Soil C & Soil D & & Soil A & \\
\hline \multicolumn{2}{|c|}{ Soil washing protgocol } & \multicolumn{4}{|c|}{ Protocol 1} & Protocol 2 & Protocol 3 & Protocol 4 \\
\hline${ }^{134} \mathrm{Cs}+{ }^{137} \mathrm{Cs}$ & {$[\mathrm{Bq} / \mathrm{kg}]$} & 12,600 & 9,200 & 12,500 & 5,400 & 12,100 & 12,500 & 12,000 \\
\hline \multicolumn{5}{|c|}{ Initioal soil washing } & Scrubbing & & & \\
\hline \multirow{3}{*}{$\begin{array}{l}\text { Plant matter separetion } \\
\text { and second soil washing }\end{array}$} & Plant matter separetion & O & O & $\bigcirc$ & 0 & - & $\bigcirc$ & $\bigcirc$ \\
\hline & Adsorbent addition & 0 & 0 & 0 & O & O & - & O \\
\hline & Grinding & $\bigcirc$ & 0 & O & $\bigcirc$ & $\bigcirc$ & $\bigcirc$ & - \\
\hline
\end{tabular}

* ' $\bigcirc$ ' in the table show the work carried out in the process of plant separation and second soil washing. 
the once-treated soil from the washed wastewater. The separated washed soil was put into the drum washer again after its weight was checked. Water, equivalent to half the weight of the once-treated soil, the adsorbent, equivalent to one percent of the weight of the once-treated soil (Katsuri Inc., with powdered hard zeolite of $75 \mu \mathrm{m}$ or lower), and an iron ball for grinding were put into the drum washer to perform a second washing for one minute at $40 \mathrm{rpm}$.

After the second washing, the slurry was moved to another $20 \mathrm{~L}$ plastic bucket. The slurry was gravity-separated, at the classification point of $75 \mu \mathrm{m}$, to separate the twice-treated soil from the second-washing drainage water. Some of the twice-treated soil was classified into size ranges using stainless steel testing screens and experimental shaking screens with $75 \mu \mathrm{m}$, $125 \mu \mathrm{m}, 250 \mu \mathrm{m}$ and $500 \mu \mathrm{m}$ meshes (Fritsch Japan Co., Ltd., 03-505).

The initial- and second-washed wastewaters were left to stand for over 30 minutes to separate the sediment from the muddy water. Flocculation agents (Taki Chemical Co., Ltd., PAC) (Nippon Poly-Glu Co., Ltd., PGa21Ca) were added to the two muddy water samples at concentrations of $200 \mathrm{mg} / \mathrm{L}$ and $50 \mathrm{mg} / \mathrm{L}$, respectively, to perform the coagulation and sedimentation processes. After the coagulation and sedimentation processes, the supernatant liquid was separated from the sediment. This sediment, mixed with the earlier sediment, was dehydrated using a filter press (Nippon Roka Co., Ltd., FS-076) to separate the filtrate water from the dehydrated cake. Figure 1 shows the sequence of the soil washing test.

\section{Confirmation Items Including Decontamination Effect}

\section{(1) Decontamination and weight reduction effects}

In order to check the effect of soil washing on decontamination and weight reduction, the

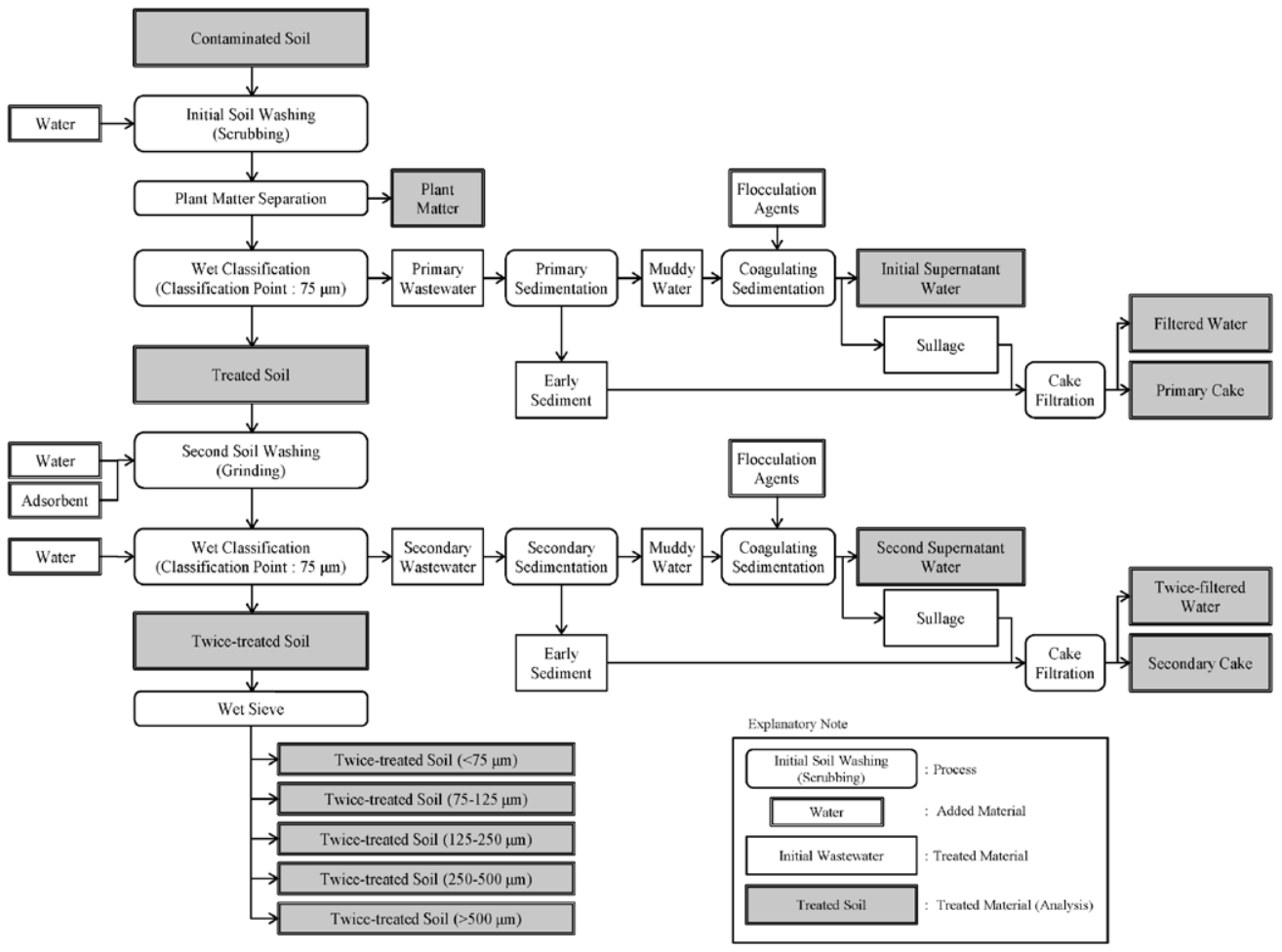

Figure 1 Schematic diagram of a soil washing test 
concentration, weight, and moisture content of the radioactive Cs in the soil and drainage water before and after the washing process were measured. In addition, the particle size distribution of the soil was measured before and after the washing process.

\section{(2) The influence of soil properties on soil washing}

In order to check the decontamination and weight reduction effects of soil washing, the organic carbon concentration and cation exchange capacity (CEC) of the contaminated soil were measured before washing. In addition, as the soil is washed using water, the heavy metals contained in the soil, such as lead and arsenic, may elute to cause yet another form of soil contamination. In order to determine the potential for the re-elution of heavy metals, the amount of heavy metals contained in the soil before the washing process, in the initial dehydrated cake, and the secondary dehydrated cake, was measured.

\section{Analysis Method}

\section{(1) Measurement of radioactive Cs concentration}

The concentration of radioactive Cs was measured in accordance with the method described in the manual on the measurement of the radioactivity of foods in the event of an emergency. A U-8 container and a 2-L Marinelli beaker were used for the soil sample and water sample, respectively. For the measurements, a gamma-ray spectrometer, based on a germanium semiconductor detector was used (manufactured by Canberra, 7500SL (P-type standard coaxial model) relative efficiency: $25 \%$, measurement time: 1,000 seconds).

\section{(2) Measurement of heavy metals etc.}

The heavy metals contained in the soil were analyzed according to the items that fall under the category of class II specified chemical substances stipulated in the Soil Contamination Countermeasures Act.

The soil elution amount and the soil content were analyzed in accordance with methods that comply with the Ministry of Environment Notification No. 18, and the Ministry of Environment Notification No. 19 , respectively.

\section{(3) Cation exchange capacity measurement}

The semimicro-Schollenberger method was used to measure the CEC of the soil.

\section{(4) Organic carbon measurement}

The organic carbon in the soil was measured using the CHN coder method. In addition, as pretreatment, the soil sample was air-dried and visible plant matter eliminated.

\section{(5) Particle size distribution measurement}

The particle size distribution in the soil was measured using a method compliant with JIS A 1204 (Test method for particle size distribution of soils). 
Table 2 Results of testing multistep soil washing (Cases 1-4)

\begin{tabular}{|c|c|c|c|c|c|c|c|}
\hline \multirow{2}{*}{\multicolumn{4}{|c|}{$\begin{array}{c}\text { Case number } \\
\text { Soil } \\
\text { Soil washing protocol }\end{array}$}} & $\begin{array}{l}\text { Case } 1 \\
\text { Soil A }\end{array}$ & $\begin{array}{l}\text { Case } 2 \\
\text { Soil B }\end{array}$ & $\begin{array}{l}\text { Case } 3 \\
\text { Soil C }\end{array}$ & $\begin{array}{l}\text { Case } 4 \\
\text { Soil D }\end{array}$ \\
\hline & & & & \multicolumn{4}{|c|}{ Protocol 1} \\
\hline \multirow{5}{*}{\multicolumn{2}{|c|}{ Contaminated soil }} & ${ }^{134} \mathrm{Cs}+{ }^{137} \mathrm{Cs}$ & {$[\mathrm{Bq} / \mathrm{kg}]$} & 12,000 & 9,200 & 12,500 & 5,400 \\
\hline & & Dry weight & {$[\mathrm{kg}]$} & 8.65 & 8.28 & 7.86 & 9.30 \\
\hline & & Gravel fraction & {$[\%]$} & 7.7 & 12.9 & 8.0 & 3.6 \\
\hline & & Sand fraction & {$[\%]$} & 62.1 & 53.3 & 46.7 & 82.4 \\
\hline & & Clay and silt fraction & {$[\%]$} & 30.2 & 33.8 & 45.3 & 14.0 \\
\hline \multirow{34}{*}{$\begin{array}{l}\text { Treated materials } \\
\text { from the soil } \\
\text { washing process }\end{array}$} & \multirow[t]{3}{*}{ Treated soil } & ${ }^{134} \mathrm{Cs}+{ }^{137} \mathrm{Cs}$ & {$[\mathrm{Bq} / \mathrm{kg}]$} & 2,800 & 2,110 & 4,500 & 1,880 \\
\hline & & Dry weight & {$[\mathrm{kg}]$} & 6.65 & 7.27 & 7.49 & 8.89 \\
\hline & & $\begin{array}{l}\text { Rate of recovery for } \\
\text { treated soil }\end{array}$ & {$[\%]$} & 76.9 & 87.8 & 95.3 & 95.6 \\
\hline & \multirow[t]{3}{*}{ Plant matter } & ${ }^{134} \mathrm{Cs}+{ }^{137} \mathrm{Cs}$ & {$[\mathrm{Bq} / \mathrm{kg}]$} & 30,000 & 7,700 & 6,100 & 24,000 \\
\hline & & Dry weight & {$[\mathrm{kg}]$} & 0.06 & 0.06 & 0.04 & 0.04 \\
\hline & & Enrichment ratio ${ }^{\text {a) }}$ & {$[-]$} & 2.5 & 0.84 & 0.49 & 4.4 \\
\hline & \multirow[t]{2}{*}{ Primary supernatant water } & ${ }^{134} \mathrm{Cs}+{ }^{137} \mathrm{Cs}$ & {$[\mathrm{Bq} / \mathrm{L}]$} & N.D. b) & N.D. & N.D. & N.D. \\
\hline & & Volume & {$[\mathrm{L}]$} & 3.09 & 2.85 & 2.56 & 4.80 \\
\hline & \multirow[t]{2}{*}{ Filtered water } & ${ }^{134} \mathrm{Cs}+{ }^{137} \mathrm{Cs}$ & {$[\mathrm{Bq} / \mathrm{L}]$} & N.D. & N.D. & N.D. & N.D. \\
\hline & & Volume & {$[\mathrm{L}]$} & 3.79 & 1.91 & 2.87 & 1.92 \\
\hline & \multirow[t]{3}{*}{ Primary cake } & ${ }^{134} \mathrm{Cs}+{ }^{137} \mathrm{Cs}$ & {$[\mathrm{Bq} / \mathrm{kg}]$} & 21,100 & 13,300 & 18,700 & 22,700 \\
\hline & & Dry weight & {$[\mathrm{kg}]$} & 2.47 & 2.36 & 2.19 & 0.64 \\
\hline & & Enrichment ratio a) & {$[-]$} & 1.8 & 1.5 & 1.5 & 4.2 \\
\hline & \multirow[t]{2}{*}{ Secondary supernatant water } & ${ }^{134} \mathrm{Cs}+{ }^{137} \mathrm{Cs}$ & {$[\mathrm{Bq} / \mathrm{L}]$} & N.D. & N.D. & N.D. & N.D. \\
\hline & & Volume & {$[\mathrm{L}]$} & 6.88 & 9.34 & 8.07 & 9.91 \\
\hline & \multirow[t]{2}{*}{ Twice-filtered water } & ${ }^{134} \mathrm{Cs}+{ }^{137} \mathrm{Cs}$ & {$[\mathrm{Bq} / \mathrm{L}]$} & N.D. & N.D. & N.D. & N.D. \\
\hline & & Volume & {$[\mathrm{L}]$} & 2.13 & 3.34 & 3.70 & 1.51 \\
\hline & \multirow[t]{3}{*}{ Secondary cake } & ${ }^{134} \mathrm{Cs}+{ }^{137} \mathrm{Cs}$ & {$[\mathrm{Bq} / \mathrm{kg}]$} & 28,000 & 14,500 & 15,700 & 16,400 \\
\hline & & Dry weight & {$[\mathrm{kg}]$} & 0.43 & 0.79 & 1.14 & 0.38 \\
\hline & & Enrichment ratio a) & {$[-]$} & 2.3 & 1.6 & 1.3 & 3.0 \\
\hline & \multirow[t]{5}{*}{ Twice-treated soil } & ${ }^{134} \mathrm{Cs}+{ }^{137} \mathrm{Cs}$ & {$[\mathrm{Bq} / \mathrm{kg}]$} & 1,300 & 1,400 & 3,300 & 1,110 \\
\hline & & Dry weight & {$[\mathrm{kg}]$} & 5.37 & 4.34 & 4.05 & 7.83 \\
\hline & & Gravel fraction & {$[\%]$} & 12.9 & 19.5 & 11.2 & 4.7 \\
\hline & & Sand fraction & {$[\%]$} & 83.3 & 74.3 & 80.0 & 91.8 \\
\hline & & Clay and silt fraction & {$[\%]$} & 3.8 & 6.2 & 8.2 & 3.5 \\
\hline & \multicolumn{2}{|c|}{ Rate of recovery for twice-treated soil } & {$[\%]$} & 62.1 & 52.4 & 51.5 & 84.2 \\
\hline & \multicolumn{2}{|c|}{ Percentage of ${ }^{134} \mathrm{Cs}+{ }^{137} \mathrm{Cs}$ decontamination } & [\%] & 89.2 & 84.8 & 73.6 & 79.4 \\
\hline & \multirow[t]{5}{*}{ Thrice-treated soil } & ${ }^{134} \mathrm{Cs}+{ }^{137} \mathrm{Cs}$ & {$[\mathrm{Bq} / \mathrm{kg}]$} & 1,300 & 1,400 & 3,300 & 1,110 \\
\hline & & Dry weight & {$[\mathrm{kg}]$} & \multicolumn{4}{|c|}{ Not Analyzed } \\
\hline & & Gravel fraction & {$[\%]$} & \multicolumn{4}{|c|}{ Not Analyzed } \\
\hline & & Sand fraction & {$[\%]$} & \multicolumn{4}{|c|}{ Not Analyzed } \\
\hline & & Clay and silt fraction & {$[\%]$} & \multicolumn{4}{|c|}{ Not Analyzed } \\
\hline & \multicolumn{2}{|c|}{ Rate of recovery for thrice-treated soil } & {$[\%]$} & \multicolumn{4}{|c|}{ Not Analyzed } \\
\hline & \multicolumn{2}{|c|}{ Percentage of ${ }^{134} \mathrm{Cs}+{ }^{137} \mathrm{Cs}$ decontamination } & {$[\%]$} & 94.4 & 89.9 & 77.6 & 83.9 \\
\hline
\end{tabular}

* Comparison of test results at the time of processing 4 soils, using same soil washing protocol.

a) Enrichment ratio $=\left({ }^{134} \mathrm{Cs}+{ }^{137} \mathrm{Cs}\right.$ of treated materials $) /\left({ }^{134} \mathrm{Cs}+{ }^{137} \mathrm{Cs}\right.$ of contaminated soil $)$.

b) N.D.=Not Detected.

\section{Results and Discussion}

\section{The Radioactive Cs-Contaminated Soil Decontamination and Weight Reduction Effects of Multistep Soil Washing}

Table 2 shows the results of the multistep soil washing test for Cases 1-4.

The decontamination effect was evaluated based on the efficiency of radioactive Cs removal from the soil after multistep soil washing. Although the radioactive Cs concentrations in the soils were $12,000 \mathrm{~Bq} / \mathrm{kg}$ (Case 1), 9,200 Bq/kg (Case 2), 12,500 Bq/kg (Case 3) and 5,400 Bq/kg (Case 4) before soil washing, these values decreased to 2,800 Bq/kg (Case 1), 2,110 Bq/kg (Case 2), 4,500 Bq/kg (Case 3) and 1,880 Bq/kg (Case 4) after the initial washing. The initial 
washing and plant matter separation removed $60-80 \%$ of the radioactive Cs from the contaminated soil. The second washing, during which adsorbent addition and grinding were performed, decreased the radioactive Cs concentrations in the twice-treated soils to $1,300 \mathrm{~Bq} / \mathrm{kg}$ (Case 1), $1,400 \mathrm{~Bq} / \mathrm{kg}$ (Case 2), 3,300 Bq/kg (Case 3) and 1,110 Bq/kg (Case 4). The efficiency of radioactive Cs removal from the respective soils was, therefore, $89.2 \%$ (Case 1), $84.8 \%$ (Case 2), $73.6 \%$ (Case 3) and 79.4\% (Case 4), which were within the range of 70-90\%, regardless of the radioactive $\mathrm{Cs}$ concentrations and the particle size distribution of the contaminated soils. In all cases, the second washing increased the efficiency of radioactive Cs removal from the washed soil by approximately $10 \%$.

The weight reduction effect was evaluated based on the weight soil collection rate, after washing. The recovery rate for the once-treated soils was: $76.9 \%$ (Case 1), $87.8 \%$ (Case 2), 95.3\% (Case 3) and 95.6\% (Case 4), and for the twice-treated soils: $62.1 \%$ (Case 1), 52.4\% (Case 2), 51.5\% (Case 3) and 84.2\% (Case 4). The Cs removal from the once-treated soils after plant matter separation reduced the dry-weight percentage in the contaminated soils by 4.4-23.1\%. When the samples were washed a second time, the dry weight percentage was reduced to $15.8-48.5 \%$. In this test, the washed slurry was wet-classified at the classification point of $75 \mu \mathrm{m}$, and grains of $75 \mu \mathrm{m}$ or larger were collected as washed soils. Therefore, if the contaminated soils before washing contained high proportions of clay and silt fractions with a particle diameter of $75 \mu \mathrm{m}$ or smaller, the fraction of the soils larger than the sand fraction with a diameter of $75 \mu \mathrm{m}$ or larger was reduced, resulting in a decrease in the Cs removal rate from the twice-treated soils. As a result, when the proportion of clay and silt fractions in the contaminated soils was $30-40 \%$, the Cs removal rate from the twice-treated soils reached $50-60 \%$. When the proportion of clay and silt fractions in the contaminated soils was at the $10 \%$ level, the Cs removal rate from the twice-treated soils was around $80 \%$.

Compared to the radioactive $\mathrm{Cs}$ concentration in the contaminated soils, the radioactive Cs concentration in the separated plant matter was within the range of $0.5-4.5$ times higher/lower. From this, it was found that radioactive Cs was adsorbed to plant matter in the soils at concentrations similar to, or at higher levels than, the contaminated soils, although the concentration varied depending on the type of contaminated soil. In addition, the radioactive Cs concentration in the initial and secondary dehydrated cakes was 1.3-4.2 times higher than that in the contaminated soils, and it was found that radioactive Cs was concentrated in the dehydrated cakes.

On the other hand, in all cases, from 1 to 4, the concentration of radioactive Cs contained in the drainage waters (initial supernatant liquid, initial filtrate, secondary supernatant liquid, and secondary filtrate) was at, or below, the lower detection limit (approximately $10 \mathrm{~Bq} / \mathrm{L}$ ). It would appear that there is little possibility that the radioactive Cs contained in the soil would be eluted

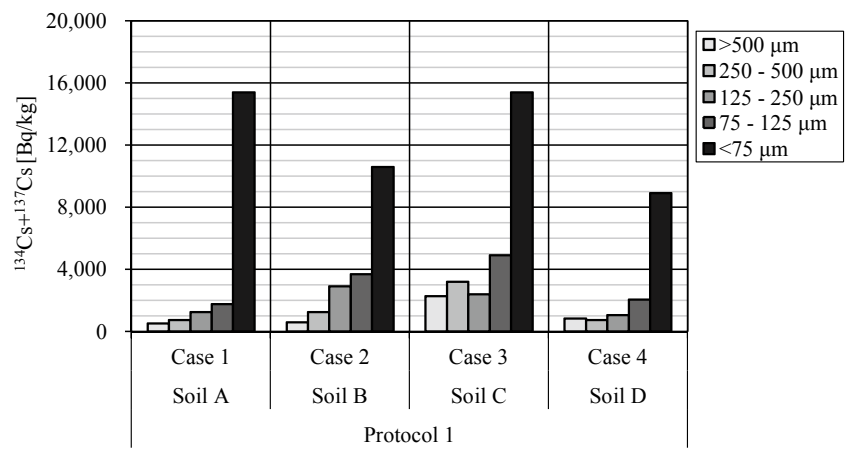

Figure $2{ }^{134} \mathrm{Cs}+{ }^{137} \mathrm{Cs}$ activity in twice-treated soil with different grain-size fractions 


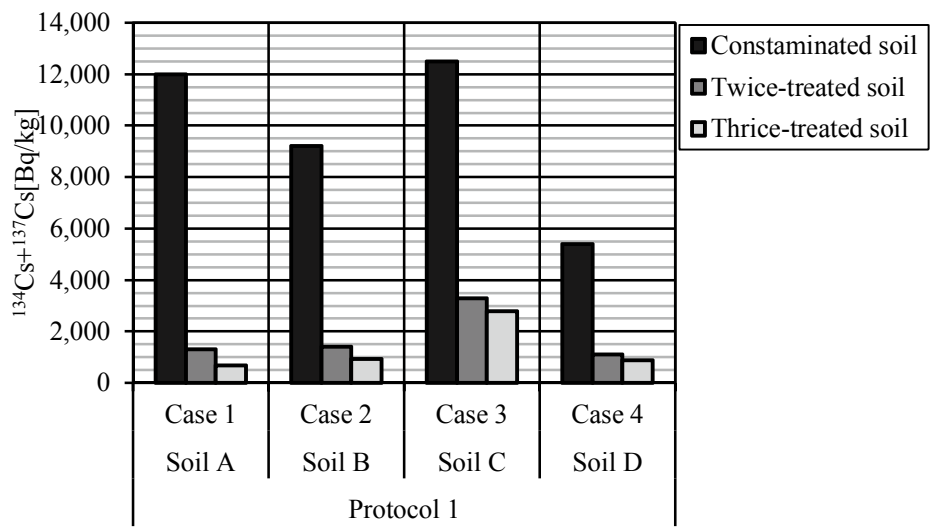

Figure $3{ }^{134} \mathrm{Cs}+{ }^{137} \mathrm{Cs}$ activity in contaminated soil, twice-treated soil, and thrice-treated soil

into water if this method were to be used.

Figure 2 shows the concentration of radioactive Cs in the twice-treated soils with different particle diameter ranges. In all cases, the radioactive Cs concentration was higher in soils with smaller particle diameters. In particular, the radioactive Cs concentration in clay and silt fractions with a particle diameter of $75 \mu \mathrm{m}$ or smaller was 2.8-7.9 times higher than that of the soils with a particle diameter of $75-125 \mu \mathrm{m}$ because radioactive Cs has a tendency to be adsorbed on fine particles. On the other hand, according to the particle size distribution in the twice-treated soils (Cases 1-4), 3-8\% of the silt fraction was present in the twice-treated soils. It is possible that the radioactive Cs concentration in the twice-treated soils was increased by the clay and silt fractions because of insufficient separation of soil particles with a diameter below $75 \mu \mathrm{m}$. Therefore, the twice-treated soils were diluted with an equal amount of water and agitated to re-slurry them. Then, the gravity separation operation was repeated three times at the classification point of $75 \mu \mathrm{m}$ in order to check the radioactive Cs concentration of the thrice-treated soils in which the clay and silt fraction was negligible. Table 2 and Figure 3 show the results. In all cases, the radioactive Cs concentration in the thrice-treated soil was lower than in the twice-treated soils. In order to improve rate of radioactive Cs removal, it is important to eliminate the clay and silt fractions using a mesh with a particle diameter of $75 \mu \mathrm{m}$ or less during multistep soil washing.

\section{Decontamination Effect Differences Due to Soil Washing Process Differences}

\section{(1) Effect of plant matter separation}

It was observed that plant matter in the contaminated soils contained high concentrations of radioactive Cs, so this was removed through gravity separation. Table 3 shows the concentration, weight and total amount of radioactive Cs in the contaminated soils, once-treated soils, eliminated plant matter, and initial dehydrated cakes of Case 5 (Soil A, Protocol 2), from which plant matter was eliminated, and Case 1 (Soil A, Protocol 1) where plant matter was not eliminated.

In Case 1 (Soil A, Protocol 1), the concentration of radioactive Cs in the eliminated plant matter was $30,000 \mathrm{~Bq} / \mathrm{kg}$, which was 2.5 times higher than that in the soil before soil washing, and it was found that the plant matter in the soils contained high concentrations of radioactive Cs. However, the removal rates in Case 1 (Soil A, Protocol 1), where plant matter was eliminated, and Case 5 (Soil A, Protocol 2), where plant matter was not eliminated, were $76.7 \%$ and 
Table 3 Results of testing multistep soil washing (Cases 1 and 5-7)

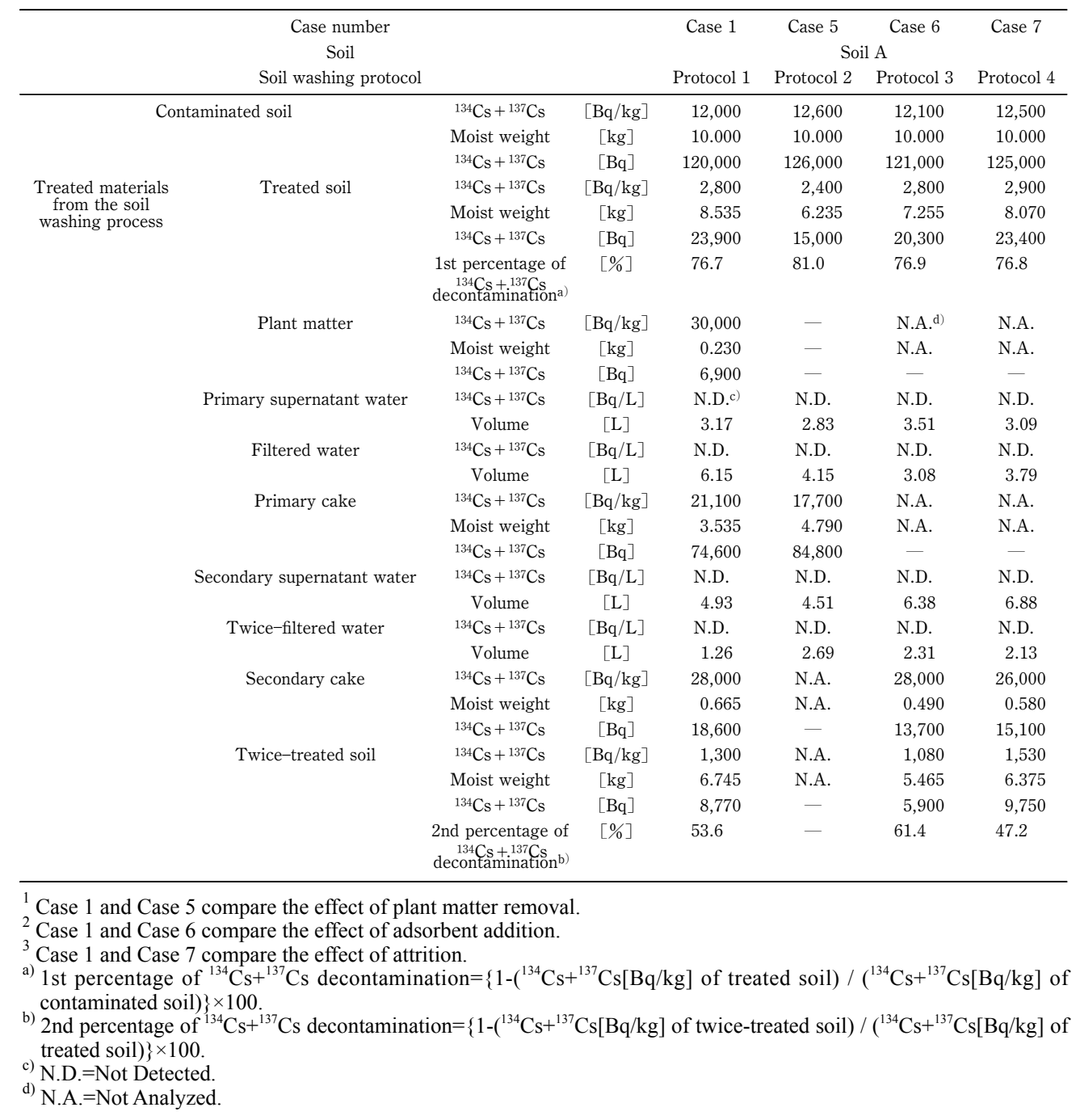

$81.0 \%$, respectively, and no significant difference was observed in the efficiency of radioactive Cs removal in the once-treated soils. The causes of this low removal efficiency are considered to be as follows: First, low amounts of plant matter were contained in the Soil A sample, which was used for the test. The wet weight of the plant matter eliminated in Case 1 (Soil A, Protocol 1) was $0.230 \mathrm{~kg}$, which was $2.3 \%$ of the wet weight of the soil before washing.

Therefore, since the concentration of radioactive Cs in the eliminated plant matter was high, but the amount of plant matter was small, the total amount of radioactive Cs contained in the plant matter was less than one-tenth of that in the once-treated soils and initial dehydrated cakes. Second, the wet classification, after the initial washing, was conducted based on wet separation. It would appear that the plant matter was removed from the contaminated soil regardless of whether the sample underwent the deliberate plant matter elimination process because the soil, with a high specific gravity, and the plant matter, with a low specific gravity, were separated in the initial washing drainage water during the gravity separation process. 


\section{(2) Effect of adsorbent addition}

Table 3 shows the concentration, weight and total amount of radioactive Cs in the once-treated soils, twice-treated soils and the secondary dehydrated cakes of Case 6 (Soil A, Protocol 3), where an adsorbent was not added, and Case 1 (Soil A, Protocol 1), when an adsorbent was added.

In the second washing process, no significant difference in the concentration of radioactive Cs was observed between the twice-treated soils and the secondary dehydrated cakes, regardless of the addition of an adsorbent. In addition, comparing the proportions of radioactive Cs present in the twice-treated soils after the second washing process, no significant difference was observed; these values were $30.1 \%$ in Case 6 (Soil A, Protocol 3) and 32.0\% in Case 1 (Soil A, Protocol 1). Initially, it was expected that the concentration of radioactive Cs in the twice-treated soils would be effectively decreased by preferentially adsorbing water-soluble radioactive Cs, which was present in the soils and eluted into water, to an adsorbent. In reality, however, adding an adsorbent contributed very little to the rate of Cs removal because radioactive Cs forms strong bonds with clay minerals in the soil and is not eluted into water as previously reported $^{3)}$.

\section{(3) Effect of grinding}

Grinding was effective in improving the rate of Cs removal in the twice-treated soils by removing the radioactive Cs adsorbed onto the soil particle surfaces. Table 3 shows the concentration, weight, and total amount of radioactive Cs in the once-treated soils, twice-treated soils, and secondary dehydrated cakes of Case 7 (Soil A, Protocol 4), where grinding was not performed during the second washing process, and Case 1 (Soil A, Protocol 1) where grinding was performed.

During the second washing process, the Cs removal rate was improved by $6.4 \%$ in Case 1 . In addition, comparing the amount of radioactive Cs present in the twice-treated soils, grinding reduced the level of radioactive Cs present by $7.3 \%$ (39.2\% in Case 7 to $32 \%$ in Case 1$)$.

It was confirmed that grinding the soil particle surfaces removed the radioactive Cs adsorbed onto the soil surface, together with the soil particle surfaces themselves, and concentrated them in the dehydrated cake.

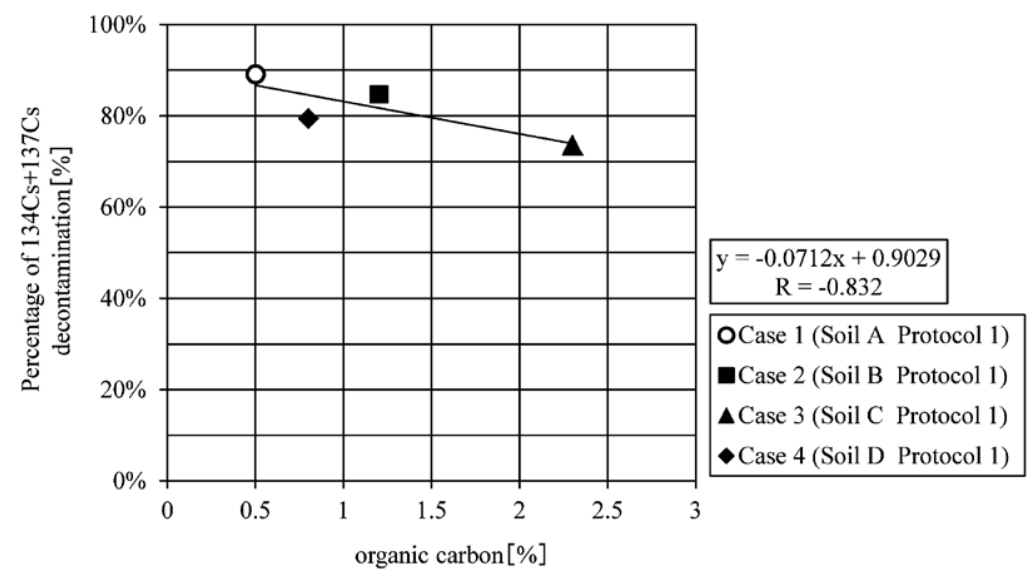

Figure 4 Relationship between organic carbon and the rate of ${ }^{134} \mathrm{Cs}+{ }^{137} \mathrm{Cs}$ decontamination 


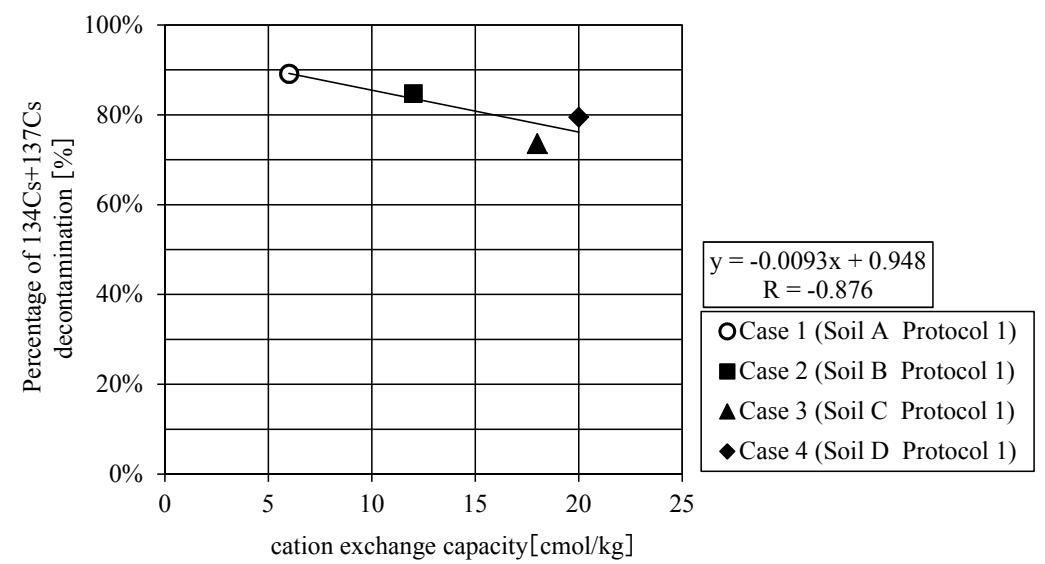

Figure 5 Relationship between cation exchange capacity and the rate of ${ }^{134} \mathrm{Cs}+{ }^{137} \mathrm{Cs}$ decontamination

Table 4 Resulting heavy metals in treated materials (Cases 1-4)

\begin{tabular}{|c|c|c|c|c|c|c|c|c|c|}
\hline \multirow{3}{*}{\multicolumn{2}{|c|}{ Case number and treated materials }} & \multicolumn{8}{|c|}{ Class 2 designated hazardous substances } \\
\hline & & \multicolumn{4}{|c|}{ Soil leachate ${ }^{\text {a) }}[\mathrm{mg} / \mathrm{L}]$} & \multicolumn{4}{|c|}{ Soil concentration $^{\text {b) }}[\mathrm{mg} / \mathrm{kg}]$} \\
\hline & & $\mathrm{Pb}$ & As & $\mathrm{F}$ & B & $\mathrm{Pb}$ & As & $\mathrm{F}$ & $\mathrm{B}$ \\
\hline \multirow{4}{*}{$\begin{array}{c}\text { Case 1 } \\
\text { (Soil A Protocol 1) }\end{array}$} & Contaminated soil & N.D. c) & N.D. & N.D. & N.D. & N.D. & N.D. & 69 & N.D. \\
\hline & Primary cake & N.D. & N.D. & N.D. & N.D. & N.D. & N.D. & 91 & N.D. \\
\hline & Secondary cake & N.D. & 0.001 & 0.42 & N.D. & 9 & N.D. & N.D. & N.D. \\
\hline & Twice-treated soil & N.D. & N.D. & N.D. & N.D. & N.D. & N.D. & N.D. & N.D. \\
\hline \multirow{4}{*}{$\begin{array}{c}\text { Case } 2 \\
\text { (Soil B Protocol 1) }\end{array}$} & Contaminated soil & 0.002 & N.D. & 0.13 & N.D. & 18 & N.D. & N.D. & N.D. \\
\hline & Primary cake & N.D. & N.D. & 0.21 & 0.01 & 26 & N.D. & N.D. & N.D. \\
\hline & Secondary cake & 0.001 & 0.002 & 0.34 & 0.01 & 33 & N.D. & N.D. & N.D. \\
\hline & Twice-treated soil & N.D. & N.D. & 0.15 & N.D. & 5 & N.D. & N.D. & N.D. \\
\hline \multirow{4}{*}{$\begin{array}{c}\text { Case } 3 \\
\text { (Soil C Protocol 1) }\end{array}$} & Contaminated soil & 0.002 & 0.001 & 0.49 & 0.01 & 18 & N.D. & 100 & N.D. \\
\hline & Primary cake & N.D. & N.D. & 0.23 & 0.01 & 33 & N.D. & 230 & N.D. \\
\hline & Secondary cake & 0.002 & 0.001 & 0.59 & 0.01 & 5 & N.D. & 220 & N.D. \\
\hline & Twice-treated soil & 0.002 & 0.001 & 0.59 & N.D. & N.D. & N.D. & N.D. & N.D. \\
\hline \multirow{4}{*}{$\begin{array}{c}\text { Case } 4 \\
\text { (Soil D Protocol 1) }\end{array}$} & Contaminated soil & N.D. & N.D. & 0.09 & 0.02 & N.D. & N.D. & N.D. & N.D. \\
\hline & Primary cake & N.D. & N.D. & N.D. & 0.02 & 19 & N.D. & 58 & N.D. \\
\hline & Secondary cake & 0.007 & 0.001 & 0.26 & 0.02 & 17 & N.D. & 76 & N.D. \\
\hline & Twice-treated soil & N.D. & 0.001 & 0.09 & N.D. & N.D. & N.D. & N.D. & N.D. \\
\hline \multicolumn{2}{|c|}{ Designation standard } & 0.01 & 0.01 & 0.8 & 1 & 150 & 150 & 4,000 & 4,000 \\
\hline \multicolumn{2}{|c|}{ Detamination limit } & 0.001 & 0.001 & 0.08 & 0.01 & 5 & 2 & 50 & 5 \\
\hline
\end{tabular}

a) Soil leachate: Quantity of the toxic substance eluted from soil to water.

b) Soil concentration: Quantity of the toxic substance taken into the body when contaminated soil is ingested.

c) N.D. $=$ Not Detected.

${ }^{*} \mathrm{Cd}, \mathrm{Cr}^{6+}, \mathrm{CN}, \mathrm{Hg}$, and Se were not detected in all test cases and all treated materials.

\section{Influence of Soil Properties on Soil Washing}

Figure 4 shows the relationship between organic carbon in the contaminated soils and the rate of radioactive Cs removal, while Figure 5 shows the relationship between the CEC and the rate of radioactive Cs removal. Both these figures are based on results from Cases 1-4.

According to Figure 4 and Figure 5, the reduction in radioactive Cs declined as the organic carbon and CEC increased. The correlation coefficients between the rate of radioactive Cs removal and organic carbon, and between the rate of radioactive Cs removal and CEC were -0.832 and -0.876 , respectively. The cause of the negative correlation is thought to be twofold: First, part of the radioactive Cs on the soil surface is adsorbed into organic substances in the 
soil, such as plant matter ${ }^{5)}$, and so the concentration of Cs is intrinsically linked with the amount of organic matter. In the experiments, the rate of radioactive Cs removal likely declined because organic substances were not eliminated by the soil washing process, causing a relative increase in the amount of organic substances, and therefore radioactive Cs, in the contaminated soil.

Second, the CEC, which shows the number of cations which can be retained in the soil, is also linked to the concentration of radioactive Cs. If the CEC is high, it means the number of cations, including radioactive Cs ions, per unit weight that can be adsorbed into the soil is high. Therefore, it is likely that the rate of radioactive Cs removal declined because soil, into which a larger amount of radioactive Cs was adsorbed, was included in the soil that underwent secondary soil washing.

Table 4 shows the concentration of heavy metals before and after multistep soil washing. In four kinds of contaminated soils, before undergoing multistep soil washing, contamination due to heavy metals was not observed. In addition, in the twice-treated soils, initial dehydrated cakes and secondary dehydrated cakes, which were generated as a result of multistep soil washing, the soil elution amount and the soil content of particular heavy metals did not exceed the criteria stipulated in the Soil Contamination Countermeasures Act. In this test, only water was used to clean the soils; the $\mathrm{pH}$ levels of the soil and water do not change significantly throughout the process. Therefore, the risk of heavy metal re-elution and subsequent recontamination is low, even if the radioactive Cs-contaminated soils are washed using only water.

\section{Conclusions}

Multistep soil washing experiments were conducted using radioactive Cs-contaminated soils collected from the Fukushima Prefecture and Inzai City, Chiba Prefecture.

As a result of initial and secondary washing, the radioactive Cs concentrations of the contaminated soils, which were initially between $9,200-12,500 \mathrm{~Bq} / \mathrm{kg}$, were reduced to 1,300 $3,300 \mathrm{~Bq} / \mathrm{kg}$. The rate of radioactive Cs removal was $73-90 \%$. In one case, where soil with a radioactive $\mathrm{Cs}$ concentration of $5,400 \mathrm{~Bq} / \mathrm{kg}$ was washed, the radioactive Cs concentration of the twice-treated soil was reduced to $1,110 \mathrm{~Bq} / \mathrm{kg}$, giving a rate of radioactive Cs removal of $79.4 \%$. Regardless of the radioactive Cs concentration and the soil properties, there was no significant difference in the removal rate of radioactive Cs removal. The radioactive Cs concentration in twice-treated soils tended to be higher in soils with smaller diameter particles. In particular, the radioactive Cs concentration in the clay and silt fractions, with a particle diameter of $75 \mu \mathrm{m}$, was 2.8-7.9 times higher than that in soils with a particle diameter of 75-125 $\mu \mathrm{m}$. Securely eliminating the clay and silt fractions was the most effective way of improving the rate of radioactive Cs removal from the twice-treated soils.

The efficiency of collection from the twice-treated soil is dependent on the proportion of the clay and silt fractions in the contaminated soil. When contaminated soils, in which the proportion of the clay and silt fractions was around $30 \%$, were washed, the recovery rate from the twice-treated soil was between $50-60 \%$. Collecting more than $50 \%$ of the contaminated soil as twice-treated soil, radioactive Cs-contaminated soil was reduced to the weight ratio of radioactive Cs-contaminated soil to $50 \%$ or lower. Since multistep soil washing reduces the weight ratio of contaminated soil by about half, it is expected to be utilized to reduce the weight of radioactive Cs-contaminated soils, enabling effective storage.

Multistep soil washing experiments were conducted with different plant matter elimination and secondary washing processes. The results confirmed that radioactive Cs was adsorbed to 
plant matter in the contaminated soils in high concentrations. In addition, grinding the soil surface improved the rate of radioactive Cs removal from the twice-treated soils. On the other hand, since the radioactive Cs contained in the soils formed strong bonds with the soil minerals and did not elute into water, adding an adsorbent during soil washing contributed very little to improving the rate of radioactive Cs removal. Furthermore, radioactive cesium did not elute into the treatment water, even though only water was used. In addition, no elution of heavy metals was observed from the samples used in this study. Therefore, there is little risk that the washing drainage water generated by this method would cause further soil contamination.

It was suggested that the rate of radioactive Cs removal had a negative correlation with the proportion of organic carbon in the contaminated soils as well as the CEC.

This test summarizes the results of the "Study On Multistage Soil Decontamination Treatment for the Radioactive Cesium-Contaminated Soil Mixed With Plants or Vegetables" conducted in 2011 as part of "Decontamination Pilot Projects for the Environmental Remediation of Evacuation Areas Contaminated With Radioactive Materials Discharged From The Fukushima Daiichi Nuclear Power Plant Accident" which was undertaken by the Japan Atomic Energy Agency, contracted by the Cabinet Office.

\section{References}

1) Ministry of the Environment, Josen Kankei Gaidorain, Ministry of the Environment, Tokyo, 2-63-2-65, (2011). [in Japanese]

2) Jiban Kogaku Kai, Zoku Dojo Chikasuiosen-notyosa Yosoku Taisaku, Jiban Kogaku Kai, Tokyo, 86-89, ISBN 978-4-88644-924-5 (2008). [in Japanese]

3) O. Nakamura, Y. Adachi, S. Iwata, Tutinokoroidogensyo Tutimizukankyonobutsurikagakutokogakutekikiso, Japan Scientific Societies Press, Tokyo, 23-41, ISBN 978-4762230103 (2003). [in Japanese]

4) National Institute for Agro-Environmental Sciences, Soil Database Browsing System, http://agrimesh. dc.affrc.go.jp/soil_db/index.phtml. [in Japanese]

5) H. Tsukada, A. Takeda, S. Hisamatsu, J. Inaba, "Concentration and specific activity of fallout ${ }^{137} \mathrm{Cs}$ in extracted and particle-size fractions of cultivated soils," J. Environ. Radioact., 99:6, 875-881 (2008). 